\title{
Pain Assessment and Treatment in Dementia at the Time of Coronavirus Disease COVID-19
}

\begin{abstract}
Damiana Scuteri ${ }^{1}$, Marta Matamala-Gomez ${ }^{2}$, Sara Bottiroli ${ }^{3,4}$, Maria Tiziana Corasaniti ${ }^{5,6}$, Roberto De Icco ${ }^{7,8}$, Giacinto Bagetta ${ }^{1 *}$ and Paolo Tonin ${ }^{9}$

${ }^{1}$ Pharmacotechnology Documentation and Transfer Unit, Preclinical and Translational Pharmacology, Department of Pharmacy, Health and Nutritional Sciences, University of Calabria, Rende, Italy, ${ }^{2}$ "Riccardo Massa" Department of Human Sciences for Education, University of Milano-Bicocca, Milan, Italy, ${ }^{3}$ Giustino Fortunato University, Benevento, Italy, ${ }^{4}$ IRCCS Mondino Foundation, Pavia, Italy, ${ }^{5}$ Department of Health Sciences, University "Magna Graecia" of Catanzaro, Catanzaro, Italy, ${ }^{6}$ School of Hospital Pharmacy, University "Magna Graecia" of Catanzaro, Catanzaro, Italy, ${ }^{7}$ Neurorehabilitation Unit, IRCCS Mondino Foundation, Pavia, Italy, ${ }^{8}$ Department of Brain and Behavioral Sciences, University of Pavia, Pavia, Italy,

${ }^{9}$ Regional Center for Serious Brain Injuries, S. Anna Institute, Crotone, Italy
\end{abstract}

Keywords: pain, dementia, COVID-19, assessment, telemedicine

\section{INTRODUCTION}

The infection of severe acute respiratory syndrome coronavirus (SARS-CoV) 2 has raised rapidly from the outbreak in Wuhan within the Chinese Hubei province all over the world resulting in a pandemic emergency, which has remarkably affected the Italian population since February 21, 2020 (1). COVID-19 (COrona VIrus Disease 2019) presents the highest rate of severity and mortality in the elderly, characterized by several comorbidities contributing to a worse prognosis (2). This is exacerbated by the circulation and spread in long-term care facilities (3). Among the concurrent chronic conditions affecting the aged patients and the oldest old, one of the most frequent is represented by cognitive impairment in dementia, known as Alzheimer's disease and related dementias (ADRD) (4). It is known that age represents a highest risk factor for pain and dementia (5). In addition, about half of the people suffering with dementia experience regular pain (6). Pain can be encountered in different types of dementia, such as Alzheimer's disease $(\mathrm{AD})$, vascular dementia (VaD), fronto-temporal dementia (FTD), and Parkinson's disease (PD), and it could appear in different forms (e.g., nociceptive pain, neuropathic pain, and central pain) (5). Importantly, the occurrence of pain in dementia could lead to further complications in the patients' healthcare routine. At this moment, due to the COVID-19 emergency, a large amount of old people presenting dementia and pain cannot attend to the hospital to receive their usual healthcare routine to manage pain. In this regard, the introduction of new digital technologies in the field of medicine - commonly known as "telemedicine" or "telehealth" (7) — can pave the way for treating pain in patients with dementia from the comfort of their own home (8).

\section{DEMENTIA, PAIN, AND COVID-19}

ADRD affect some 50 million people worldwide (9) and 900-1,000 per 100,000 inhabitants in Italy (10). The $12 \%$ of COVID-19 positive dead patients in Italy suffered from dementia (11), and $43 \%$ of deaths occurs in the oldest old (12). Apart from being aged, demented patients may have difficulties to remember preventative measures, thus resulting in a higher risk of infection, even more in nursing-home residents (4). Moreover, the mental and cognitive health of demented patients can be worsened by COVID-19. These patients suffer from several behavioral symptoms, like agitation and aggression, known as behavioral and psychological symptoms of dementia (BPSD), which can be enhanced by social distancing (13). A greater concern is for patients in need of hospitalization for COVID-19, since a new environment is proven to increase BPSD (14). Losing face-to-face contact 
with people familiar to the patients can bear a remarkable burden (4), in terms both of anxiety and of cognition. Moreover, COVID19 induces delirium due to hypoxia, which can exacerbate dementia (4). Cognitive deterioration is common in course of acute respiratory distress syndrome (ARDS) and it can last also in the long term, complicating several aspects, such as memory and attention $(15,16)$. In particular, COVID-19 seems to be associated with neurologic manifestations as confusion (9\%), dizziness (17\%), impairment of consciousness (8\%), risk of stroke (3\%), anosmia (6\%), hypogeusia (6\%), and ataxia (1\%) (17). Moreover, neuropathies can also occur (16). This issue can play a pivotal role in patients affected by ADRD, since they often present mixed pain states like osteoarthrosis and diabetic neuropathy, due to their advanced age (18). Mobility, already impaired by these conditions, can result in being very difficult to recover after hospitalization, mainly in intensive care units (ICU). The issue of worsened conditions is even more worrying in this period in which follow-up and accurate review of therapy against BPSD are postponed in order to reduce the risk of contagion (13).

In this field, pain is considered one of the most important causes of BPSD (19). In particular, the BPSD can arise as a result of pain through agitation or aggression, representing a stressful factor for both the patients and the caregivers (6). Another important issue is the impact of neuropathological changes occurring in dementia, which could affect patients' pain perception (20). Concerning this, it is known that in patients with ADRD the neuropathological changes occurring after the onset of the clinical condition have a greater impact in the medial pain system than on the lateral pain system (20). This means that in patients presenting $\mathrm{ADRD}$, there is a higher impairment of the cognitive-evaluative and motivational-affective aspects of pain than in sensory-discriminative ones (20). However, in patients with $\mathrm{VaD}$, lesions in white matter lead to several disconnections between brain areas in a neurobiological process known as "deafferentation" and provokes an increase in the motivationalaffective aspects of pain (6). This type of pain-commonly known as "central neuropathic pain" - has also been shown in patients with stroke $(21)$, and with $\operatorname{VaD}(22,23)$. Nevertheless, in FTD patients the atrophy in the prefrontal cortex can lead to a decrease in the motivational-affective aspects of pain, similarly to those presenting ADRD (24). Overall, the alterations in both the afferent transmission pathways and the endogenous descending inhibitory transmission control systems lead to an altered pain processing in patients with dementia (25). Moreover, it has been shown that the more severe the cognitive impairment, the bigger the difference in pain experience between demented and nondemented populations (5).

\section{PAIN ASSESSMENT AND NEURO-REHABILITATION: THE CONTRIBUTION OF TECHNOLOGY AT THE TIME OF COVID-19}

The $72 \%$ of patients older than 85 years suffer from pain (26, 27 ), and this amount can reach the $80 \%$ for nursing-home guests with ADRD (6) and definitely increase in ARDS and intubation. Pain diagnosis and assessment through self-report represents the gold standard, but it cannot be applied in patients with severe ADRD because of their limited communication skills (28). In these patients, underdiagnosed pain may induce BPSD like agitation $(29,30)$, requiring the use of neuroleptics increasing cardio cerebrovascular accidents (31) and, hence, predisposing to increased risk in course of COVID-19. In this situation, the ABCDEF bundle can be recommended: assess, prevent and manage pain; both spontaneous awakening and breathing trials; choice of sedation; delirium monitoring and management; early mobility and exercise; and family engagement and empowerment $(16,32)$. Although telemedicine can be not suitable to provide virtual neurologic examination (13), it can be very useful to manage BPSD (13) and pain (33). It can indeed represent an important option to provide accurate treatment also with drugs like opioids endowed with serious adverse reactions (34), including immune system, and thus involved in COVID-19 management (33). Therefore, the assessment of pain is fundamental to improve the quality of life and reduce the risk of death of demented patients, even more in this difficult scenario. For patients with severe dementia observational assessment tools can be applied. In particular, the Mobilization-ObservationBehavior-Intensity-Dementia (MOBID)-2 pain scale that allows the caregiver to rate the intensity of both the musculoskeletal pain, through the observation of pain behavioral indicators (pain noises, facial mimics, and defense moves) during the execution of five guided movements to unravel also hidden conditions, and the visceral pain (35). Furthermore, some reviews highlighted that the same motor rehabilitative treatment, delivered from afar or face to face, produces the same results, suggesting that telerehabilitation is not inferior in comparison with in-person therapy $(36,37)$. In this situation, motor telerehabilitation can be very useful to improve motor activity, according to the ABCDEF bundle, and tele-care may also allow to establish a safe contact with the caregiver whom can be instructed in streaming by the health assistant (38). The use of mask may prevent the assessment of facial expressions. Moreover, another assessment test for intubated patients, with specific non-verbal pain scales examined in ICU, is the Critical-Care Pain Observation Tool (CPOT) (39). This pain scale allows to observe pain also in the presence of the endotracheal tube and to evaluate the compliance with the ventilator, and it has proven to have good validity, reliability, feasibility, and clinical utility (39-41). The main features of the proposed pain assessment tools are reported in Table $\mathbf{1 .}$

Interestingly, previous investigations have described the use of telemedicine as a useful tool to follow or treat clinical populations in catastrophic situations or in public health emergencies (42). Through telemedicine systems, patients can be efficiently screened, and this could represent an effective approach in the current worldwide emergency of COVID-19. By using telemedicine systems, it is also possible to protect patients, clinicians, and the community from virus exposure (8). Moreover, telemedicine systems allow physicians and patients to be in contact anytime (24/7) through smartphones, tablet, or webcam enabled computers (8) and tackle some clinical issues related to expenses, prevalence, and other treatment barriers associated with the patients' management. In particular, 
TABLE 1 | Characteristics of the pain assessment tools useful for non-communicative patients with severe dementia and intubated.

\begin{tabular}{|c|c|c|c|c|c|c|}
\hline $\begin{array}{l}\text { Pain assessment } \\
\text { tool }\end{array}$ & $\begin{array}{l}\text { Authors and } \\
\text { year of first } \\
\text { publication }\end{array}$ & $\begin{array}{l}\text { Type of } \\
\text { scale }\end{array}$ & Number of items & $\begin{array}{l}\text { Time of } \\
\text { execution }\end{array}$ & $\begin{array}{l}\text { Qualification } \\
\text { of rater }\end{array}$ & Validity and reliability \\
\hline $\begin{array}{l}\text { Mobilization- } \\
\text { Observation- } \\
\text { Behavior- } \\
\text { Intensity- } \\
\text { Dementia } \\
\text { (MOBID)-2. }\end{array}$ & (35) & $\begin{array}{l}\text { Observational } \\
\text { scale. }\end{array}$ & $\begin{array}{l}\text { It consists of two parts of } 5 \\
\text { items each. Part 1: } \\
\text { assessment of } \\
\text { musculoskeletal pain } \\
\text { observing pain behavior } \\
\text { during the execution of five } \\
\text { guided movements. Part II: } \\
\text { assessment of pain from } \\
\text { internal organs, head and } \\
\text { skin pain behavioral } \\
\text { indicators, and localization } \\
\text { of pain crossing on pain } \\
\text { drawing. }\end{array}$ & $\begin{array}{l}\text { Time-efficient } \\
\text { in use (mean } \\
4.37 \text { min, } \\
\text { range } \\
2.0-7.0) \text {. }\end{array}$ & $\begin{array}{l}\text { Trained } \\
\text { nurse. }\end{array}$ & $\begin{array}{l}\text { Moderate to excellent agreement was } \\
\text { demonstrated for behaviors and pain } \\
\text { drawings ( } \kappa=0.41-0.90 \text { and } \kappa= \\
0.46-0.93 \text { ). } \\
\text { Inter-rater and test-retest reliability for } \\
\text { pain intensity: ICC } 0.80-0.94 \text { and } \\
0.60-0.94 \text {. } \\
\text { Internal consistency: Cronbach's } \alpha \\
\text { ranging } 0.82-0.84 \text {. } \\
\text { Good face-, construct- and } \\
\text { concurrent validity. } \\
\text { Correlation of overall pain intensity } \\
\text { with physicians' clinical examination } \\
\text { and defined pain variables (rho } \\
=0.41-0.64 \text { ). }\end{array}$ \\
\hline $\begin{array}{l}\text { Critical-Care Pain } \\
\text { Observation Tool } \\
\text { (CPOT). }\end{array}$ & (39) & $\begin{array}{l}\text { Observer } \\
\text { rated scale. }\end{array}$ & $\begin{array}{l}\text { It consists of } 4 \text { items: facial } \\
\text { expression, body } \\
\text { movement, ventilator } \\
\text { compliance, and muscle } \\
\text { tension. }\end{array}$ & $\begin{array}{l}\text { The patient is } \\
\text { observed for } \\
1 \text { min at rest } \\
\text { and during } \\
\text { and after } \\
\text { nociceptive } \\
\text { procedure. }\end{array}$ & $\begin{array}{l}\text { Trained } \\
\text { nurse. }\end{array}$ & $\begin{array}{l}\text { Inter-rater reliability: } k=0.52-0.88 \text {. } \\
\text { Acceptable reliability and validity, with } \\
\text { significant discriminant validity (paired } \\
t \text {-tests, } P \leq 0.001) \text {. Criterion validity: } \\
\text { analyses of variance ANOVA ( } P \leq \\
0.001) \text { and Spearman correlations } \\
(0.40-0.59, P \leq 0.001) \text {. }\end{array}$ \\
\hline
\end{tabular}

telemedicine has been used for pain assessment through digital diaries or personal digital assistants $(43,44)$, to provide an accurate and easy monitoring of pain symptoms. Regarding treatment delivery in pain patients, novel telemedicine strategies have been found effective to facilitate consultation and talk therapy and to provide rehabilitation pain trainings (45-49). For instance, telemedicine systems have been proposed to provide behavioral medicine interventions in chronic pain patients through a self-regulation training targeting both the sensory and affective components of pain (50). In addition, training programs through video-conferencing have been also used for pain treatments $(46,50)$.

\section{DISCUSSION}

The SARS-CoV 2 has changed the management of chronic conditions often occurring in the main target of COVID-19 represented by the aged population. One of the most common comorbidities in these patients is dementia, often accompanied by chronic pain. The assessment and management of pain in demented patients is necessary during COVID-19 pandemic emergency, and the use of telemedicine can allow a safe handling reducing the access to hospitals and clinics to contain contagion. We suggest pain management to improve the quality of life of patients and to reduce agitation (51): accurate review of analgesic and antipsychotic therapy of BPSD can reduce

\section{REFERENCES}

1. Bartolo $\mathrm{M}$, Intiso $\mathrm{D}$, Lentino $\mathrm{C}$, Sandrini G, Paolucci S, Zampolini M. Urgent measures for the containment of the coronavirus (Covid19) epidemic in the neurorehabilitation/rehabilitation departments in the cardiocerebrovascular events, an important risk factor for bad prognosis of COVID 19. Pain is often misunderstood and undertreated; therefore, educational programs for physicians and caregivers are needed $(52,53)$ to improve "pre-habilitation," the process of optimizing general health fundamental to cope better with the stress condition (16), and neurorehabilitation of demented patients after COVID 19. Furthermore, novel telemedicine systems should be also taken in consideration to provide assessment and rehabilitation pain trainings to improve neurorehabilitation of patients suffering from dementia in the new era of COVID-19.

\section{AUTHOR CONTRIBUTIONS}

DS, MC, GB, and PT have conceived the work. All authors listed have made a substantial, direct and intellectual contribution to the work, and approved it for publication.

\section{ACKNOWLEDGMENTS}

DS was a post-doc recipient of a research grant salary in the frame of a research project (tutor: GB) on Pharmacoepidemiology of drugs used in the treatment of neuropsychiatric symptoms and pain in aged (over 65) people with dementia funded by Calabria Region (POR Calabria FESR-FSE 2014/2020-Linea B) Azione 10.5.12.

phase of maximum expansion of the epidemic. Front Neurol. (2020) 11:423. doi: 10.3389/fneur.2020.00423

2. Weiss P, Murdoch DR. Clinical course and mortality risk of severe COVID-19. Lancet. (2020) 395:1014-5. doi: 10.1016/S0140-6736(20)3 0633-4 
3. McMichael TM, Clark S, Pogosjans S, Kay M, Lewis J, Baer A, et al. COVID-19 in a long-term care facility - King county, Washington, February 27-March 9, 2020. Morb Mortal Wkly Rep. (2020) 69:33942. doi: 10.15585/MMWR.MM6912E1

4. Wang H, Li T, Barbarino P, Gauthier S, Brodaty H, Molinuevo JL, et al. Dementia care during COVID-19. Lancet. (2020) 395:1190-1. doi: 10.1016/S0140-6736(20)30755-8

5. Scherder E, Herr K, Pickering G, Gibson S, Benedetti F, Lautenbacher S. Pain in dementia. Pain. (2009) 5:e803. doi: 10.1016/j.pain.2009.04.007

6. Achterberg WP, Pieper MJC, van Dalen-Kok AH, de Waal MWM, Husebo BS, Lautenbacher S, et al. Pain management in patients with dementia. Clin Interv Aging. (2013) 8:1471-82. doi: 10.2147/CIA.S36739

7. Tuckson RV, Edmunds M, Hodgkins ML. Telehealth. N Engl J Med. (2017) 377:1585-92. doi: 10.1056/NEJMsr1503323

8. Hollander JE, Carr BG. Virtually perfect? Telemedicine for Covid-19. N Engl J Med. (2020) 382:1679-81. doi: 10.1056/NEJMp2003539

9. Patterson C. World Alzheimer Report 2018. The State of the Art of Dementia Research: New Frontiers. London: Alzheimer's Disease International (ADI) (2018).

10. Feigin VL, Nichols E, Alam T, Bannick MS, Beghi E, Blake N, et al. Global, regional, and national burden of neurological disorders, 1990-2016: a systematic analysis for the global burden of disease study 2016. Lancet Neurol. (2019) 18:459-80. doi: 10.1016/S1474-4422(18)30499-X

11. Cipriani G, Di Fiorino M. Access to care for dementia patients suffering from COVID-19. Am J Geriatr Psychiatr. (2020) 28:796-7. doi: 10.1016/j.jagp.2020.04.009

12. Livingston E, Bucher K. Coronavirus disease 2019 (COVID-19) in Italy. JAMA. (2020). doi: 10.1001/jama.2020.4344

13. Brown EE, Kumar S, Rajji TK, Pollock BG, Mulsant BH. Anticipating and mitigating the impact of the COVID-19 pandemic on Alzheimer's disease and related dementias. Am J Geriatr Psychiatr. (2020) 28:71221. doi: 10.1016/j.jagp.2020.04.010

14. Kales HC, Lyketsos CG, Miller EM, Ballard C. Management of behavioral and psychological symptoms in people with Alzheimer's disease: an international Delphi consensus. Int Psychogeriatr. (2019) 31:83-90. doi: 10.1017/S1041610218000534

15. Elizabeth Wilcox M, Brummel NE, Archer K, Wesley Ely E, Jackson JC, Hopkins RO. Cognitive dysfunction in ICU patients: risk factors, predictors, and rehabilitation interventions. Crit Care Med. (2013) 41:S8198. doi: 10.1097/CCM.0b013e3182a16946

16. Simpson R, Robinson L. Rehabilitation following critical illness in people with COVID-19 infection. Am J Phys Med Rehabil. (2020) 99:4704. doi: 10.1097/PHM.0000000000001443

17. Shaikh AG, Mitoma H, Manto M. Cerebellar scholars' challenging time in COVID-19 pandemia. Cerebellum. (2020) 16:1-2. doi: 10.1007/s12311-020-01131-9

18. Scuteri D, Morrone LA, Rombolà L, Avato PR, Bilia AR, Corasaniti MT, et al. Aromatherapy and aromatic plants for the treatment of behavioural and psychological symptoms of dementia in patients with Alzheimer's disease: clinical evidence and possible mechanisms. Evidence-based complement. Altern Med. (2017) 2017:9416305. doi: 10.1155/2017/9416305

19. Corbett A, Husebo B, Malcangio M, Staniland A, Cohen-Mansfield J, Aarsland $\mathrm{D}$, et al. Assessment and treatment of pain in people with dementia. Nat Rev Neurol. (2012) 8:264-74. doi: 10.1038/nrneurol.2012.53

20. Scherder EJA, Sergeant JA, Swaab DF. Pain processing in dementia and its relation to neuropathology. Lancet Neurol. (2003) 2:677-86. doi: 10.1016/S1474-4422(03)00556-8

21. Siniscalchi A, Gallelli L, De Sarro G, Malferrari G, Santangelo E. Antiepileptic drugs for central post-stroke pain management. Pharmacol Res. (2012) 65:171-5. doi: 10.1016/j.phrs.2011.09.003

22. Achterberg WP, Scherder E, Pot AM, Ribbe MW. Cardiovascular risk factors in cognitively impaired nursing home patients: a relationship with pain? Eur J Pain. (2007) 11:707-10. doi: 10.1016/j.ejpain.2006.10.006

23. Plooij B, Swaab D, Scherder E. Autonomic responses to pain in aging and dementia. Rev Neurosci. (2011) 22:583-9. doi: 10.1515/RNS.2011.045

24. Bathgate D, Snowden JS, Varma A, Blackshaw A, Neary D. Behaviour in frontotemporal dementia, Alzheimer's disease and vascular dementia. Acta Neurol Scand. (2001) 103:367-78. doi: 10.1034/j.1600-0404.2001.2000236.x
25. Gibson SJ, Voukelatos X, Ames D, Flicker L, Helme RD. An examination of pain perception and cerebral event-related potentials following carbon dioxide laser stimulation in patients with Alzheimer's disease and age-matched control volunteers. Pain Res Manag. (2001) 6:126-32. doi: 10.1155/2001/814374

26. Achterberg WP. How can the quality of life of older patients living with chronic pain be improved? Pain Manag. (2019) 9:431-3. doi: 10.2217/pmt-2019-0023

27. Duncan R, Francis RM, Collerton J, Davies K, Jagger C, Kingston A, et al. Prevalence of arthritis and joint pain in the oldest old: findings from the newcastle 85+ study. Age Ageing. (2011) 40:752-5. doi: 10.1093/ageing/afr105

28. Scuteri D, Rombolà L, Morrone LA, Bagetta G, Sakurada S, Sakurada T, et al. Neuropharmacology of the neuropsychiatric symptoms of dementia and role of pain: essential oil of bergamot as a novel therapeutic approach. Int J Mol Sci. (2019) 20:3327. doi: 10.3390/ijms20133327

29. Husebo BS, Ballard C, Sandvik R, Nilsen OB, Aarsland D. Efficacy of treating pain to reduce behavioural disturbances in residents of nursing homes with dementia: Cluster randomised clinical trial. BMJ. (2011) 343:d4065. doi: 10.1136/bmj.d4065

30. Sampson EL, White N, Lord K, Leurent B, Vickerstaff V, Scott S, et al. Pain agitation, and behavioural problems in people with dementia admitted to general hospital wards: a longitudinal cohort study. Pain. (2015) 156:67583. doi: 10.1097/j.pain.0000000000000095

31. Schneider LS, Dagerman KS, Insel P. Risk of death with atypical antipsychotic drug treatment for dementia: meta-analysis of randomized placebo-controlled trials. J Am Med Assoc. (2005) 294:1934-43. doi: 10.1001/jama.294.15.1934

32. Marra A, Ely EW, Pandharipande PP, Patel MB. The ABCDEF bundle in critical care. Crit Care Clin. (2017) 33:225-43. doi: 10.1016/j.ccc.2016.12.005

33. Cohen SP, Baber ZB, Buvanendran A, McLean LTCBC, Chen Y, Hooten WM, et al. Pain management best practices from multispecialty organizations during the COVID-19 pandemic and public health crises. Pain Med. (2020) 21:1331-46. doi: 10.1093/pm/pnaa127

34. Morrone L, Scuteri D, Rombola L, Mizoguchi H, Bagetta G. Opioids resistance in chronic pain management. Curr Neuropharmacol. (2017) 15:444-56. doi: 10.2174/1570159x14666161101092822

35. Husebo BS, Strand LI, Moe-Nilssen R, Husebo SB, Ljunggren AE. Pain in older persons with severe dementia. Psychometric properties of the mobilization-observation-behaviour-intensity-dementia (MOBID-2) pain scale in a clinical setting. Scand J Caring Sci. (2010) 24:38091. doi: 10.1111/j.1471-6712.2009.00710.x

36. Agostini M, Moja L, Banzi R, Pistotti V, Tonin P, Venneri $\mathrm{A}$, et al. Telerehabilitation and recovery of motor function: a systematic review and meta-analysis. J Telemed Telecare. (2015) 21:202-13. doi: 10.1177/1357633X15572201

37. Laver KE, Adey-Wakeling Z, Crotty M, Lannin NA, George S, Sherrington C. Telerehabilitation services for stroke. Cochrane Database Syst Rev. (2020) 1:CD010255. doi: 10.1002/14651858.CD010255

38. Gately ME, Trudeau SA, Moo LR. In-home video telehealth for dementia management: implications for rehabilitation. Curr Geriatr Rep. (2019) 8:23949. doi: 10.1007/s13670-019-00297-3

39. Gélinas C, Fillion L, Puntillo KA, Viens C, Fortier M. Validation of the criticalcare pain observation tool in adult patients. Am J Crit Care. (2006) 15:420-7.

40. Shahiri TS, Richard-Lalonde M, Richebé P, Gélinas C. Exploration of the Nociception Level $\left(\mathrm{NOL}^{\mathrm{TM}}\right)$ Index for pain assessment during endotracheal suctioning in mechanically ventilated patients in the intensive care unit: An observational and feasibility study. Pain Manag Nurs. (2020). doi: 10.1016/j.pmn.2020.02.067

41. Varndell W, Fry M, Elliott D. A systematic review of observational pain assessment instruments for use with nonverbal intubated critically ill adult patients in the emergency department: an assessment of their suitability and psychometric properties. J Clin Nurs. (2017) 26:7-32. doi: 10.1111/jocn. 13594

42. Lurie N, Carr BG. The role of telehealth in the medical response to disasters. JAMA Intern Med. (2018) 178:745-6. doi: 10.1001/jamainternmed.20 18.1314

43. Lind L, Karlsson D, Fridlund B. Patients' use of digital pens for pain assessment in advanced palliative home healthcare. Int J Med Inform. (2008) 77:12936. doi: 10.1016/j.ijmedinf.2007.01.013 
44. Peters ML, Crombez G. Assessment of attention to pain using handheld computer diaries. Pain Med. (2007) 8:S11020. doi: 10.1111/j.1526-4637.2007.00375.x

45. Elliott J, Chapman J, Clark DJ. Videoconferencing for a veteran's pain management follow-up clinic. Pain Manag Nurs. (2007) 8:3546. doi: 10.1016/j.pmn.2006.12.005

46. Gardner-Nix J, Backman S, Barbati J, Grummitt J. Evaluating distance education of a mindfulness-based meditation programme for chronic pain management. J Telemed Telecare. (2008) 14:88-92. doi: 10.1258/jtt.2007.070811

47. McGeary DD, McGeary CA, Gatchel RJ. A comprehensive review of telehealth for pain management: where we are and the way ahead. Pain Pract. (2012) 12:570-7. doi: 10.1111/j.1533-2500.2012.00534.x

48. Naylor MR, Keefe FJ, Brigidi B, Naud S, Helzer JE. Therapeutic interactive voice response for chronic pain reduction and relapse prevention. Pain. (2008) 134:335-45. doi: 10.1016/j.pain.2007.11.001

49. Rosser BA, McCullagh P, Davies R, Mountain GA, McCracken L, Eccleston C. Technology-mediated therapy for chronic pain management: the challenges of adapting behavior change interventions for delivery with pervasive communication technology. Telemed e-Health. (2011) 17:2116. doi: $10.1089 / \mathrm{tmj} .2010 .0136$

50. Appel PR, Bleiberg J, Noiseux J. Self-regulation training for chronic pain: Can it be done effectively by telemedicine? Telemed J e-Health. (2002) 8:3618. doi: 10.1089/15305620260507495
51. Scuteri D, Rombolá L, Tridico L, Mizoguchi H, Watanabe C, Sakurada T, et al. Neuropharmacological properties of the essential oil of bergamot for the clinical management of pain-related BPSDs. Curr Med Chem. (2018) 26:3764-3774. doi: 10.2174/0929867325666180307115546

52. Scuteri D, Piro B, Morrone LA, Corasaniti MT, Vulnera M, Bagetta G. The need for better access to pain treatment: Learning from drug consumption trends in the USA. Funct Neurol. (2017) 32:229-30. doi: 10.11138/FNeur/2017.32.4.229

53. Scuteri D, Garreffa MR, Esposito S, Bagetta G, Naturale MD, Corasaniti MT. Evidence for accuracy of pain assessment and painkillers utilization in neuropsychiatric symptoms of dementia in Calabria region, Italy. Neural Regen Res. (2018) 13:1619-21. doi: 10.4103/1673-5374.237125

Conflict of Interest: The authors declare that the research was conducted in the absence of any commercial or financial relationships that could be construed as a potential conflict of interest.

Copyright (C) 2020 Scuteri, Matamala-Gomez, Bottiroli, Corasaniti, De Icco, Bagetta and Tonin. This is an open-access article distributed under the terms of the Creative Commons Attribution License (CC BY). The use, distribution or reproduction in other forums is permitted, provided the original author(s) and the copyright owner(s) are credited and that the original publication in this journal is cited, in accordance with accepted academic practice. No use, distribution or reproduction is permitted which does not comply with these terms. 